\title{
Assessment of Sustainable Development's Factors of Small and Medium-Sized Business Institutions in the Context of Covid-19
}

\author{
Sadovnikova N.A.* Demidova L.N. Zolotareva O.A. \\ Plekhanov Russian University of Economics, Moscow, Russia \\ *Corresponding author. Email: Sadovnikova.NA@rea.ru
}

\begin{abstract} businesses.

\section{INTRODUCTION}

Small and medium business is the central institutional segment that forms and implements not only economic but also a public benefit for society and ensures the growth of the country's economic potential. It is small and mediumsized businesses that have additional advantages and can maneuver in the face of rapid changes in market conditions, allow them to replace the most vulnerable places in the economy, quickly integrate into those links where it is difficult to find a niche, especially in a crisis and pandemic [1].
\end{abstract}

The article investigates the problems of the market economy, which is characterized by the effectiveness of small and medium-sized businesses. The authors carried out an excursion into the history of the development's problem of small and medium-sized businesses, identified their critical points; the assessment of the development's factors of small and medium business institutions was carried out. An assessment of the current situation in the development of small and medium-sized businesses allows us to conclude that entrepreneurship takes a social function of realizing a public good. For an entrepreneur, his activities remain the realization of his talents, skills, and abilities, bringing public benefit, rather than a profitable occupation. To assess the degree of factors' significance in dynamics, the Kendall coefficient was used, which shows a direct relationship between the factors limiting investment activity. Moreover, such an increase in factors is noticeable precisely in the dynamics of the respondents' answers among heads of small and medium-sized

Keywords: small and medium-sized businesses, institutions of small and medium-sized businesses, functioning of small and medium-sized businesses in the context of Covid-19

The Institute of Small and Medium Business, considered at the regional level of the economic system, is a filter that allows dividing the labor potential into two key groups. The first group consists of leaders of small and mediumsized businesses capable of solving complex problems (quick response to new market conditions, maximum use of the existing potential or attraction of innovations for this purpose). The second one is represented by managers who can work in a more linear and formatted manner. In a pandemic, it turned out to be difficult for many business leaders to navigate. They need to find new solutions, apply new approaches to solve problems. In this regard, the study of the factors that form the conditions for the functioning of small and medium-sized enterprises remains one of the defining tasks in the current conditions [2].

\section{RESEARCH METHODOLOGY}

Rosstat studies the conditions for the functioning of small and medium-sized businesses. For this purpose, Rosstat collected information and calculated indicators: the birth rate of organizations (the ratio of the organizations' number registered during the reporting period to the average number of organizations recorded in the Rosstat Statistical Register, expressed in ppm), the ratio of the organizations' official liquidation (the ratio of the organizations' number officially liquidated during the reporting period to the average number of organizations registered in the Statistical Register of Rosstat, expressed in $\mathrm{ppm})$, etc.

The information fund of the Automated System for Maintaining the General Set of Objects of Federal Statistical Observation (AS GS OFSO) is used as a source of information for the indicators' formation of business demography. The unit of observation for registering demographic events was the legal entity as a whole. Demographic cases of legal entities' geographically separated divisions were not considered.

In this work, the data collected in the AS of the GS OFSN were imputed using mathematical and statistical methods and the formation, based on information's edited sources, of business demography's indicators, which determine the growth of entrepreneurial activity. 
The theoretical basis of this study is formed by the general theoretical provisions of the institutional and neoinstitutional theory, the general theory of strategic management, the theory of organization, and doing business. In addition, the work uses certain provisions of the theory of state and municipal government [3-6]. This is not in proportion to the model size. The efficiency of our framework depends only on the time of a counterexample (indicate that the probabilistic safety property is violated) appears in conjectured assumptions. The earlier a counterexample appears, the more efficient our framework performs.

In Table 3, the component sizes of the M1 and M2 are also denoted as $|\mathrm{M} 1|$ and $|\mathrm{M} 2|$. The performance is measured only by total runtimes (Time) because both methods have the same amount of MQ if the model satisfies the properties. Because of the early detection cost, we can find that our methods need to spend more time than Feng et al. [23], and the cost grows with the model size. But compared with the acquirement of optimization in Tables 1 and 2, the cost is acceptable in Table 3.

\section{RESEARCH RESULT}

The institutional theory was studied by both foreign and domestic scientists: J. Keynes, R. Coase, T. Veblen, I. Prigogine, S. Kapitsa, V. Arshinov, etc. Today several theories have been formed within the framework of the institutional direction of economic's institutional changes (J. Knight, V. Ratten, Y. Hayami, D. North, V. Tambovtsev, and others) [7-10].

The studies carried out by the scientists above and other economists allowed to distribute the institutions of production into three main groups, based on their essential content and scientific characteristics: institutions - factors (property, state, firms, market institutions, peasant households, and others); institutions - conditions (traditions of the peasantry, stereotypes of economic behavior, etc.) and institutions - mechanisms (reforms, legal aspects, programs, plans, instructions, contracts, etc.).

Institutional transformations are the improvement or development of the production relations system, bringing them to conformity with the level and nature of the productive forces' development. Each of these groups influences the effectiveness of the institutions functioning with different strengths. Moreover, the problem of measuring such factors, which cannot be characterized quantitatively, creates additional problems in measuring their influence. In addition, in the Russian context of dynamically changing parameters of institutions and their permanent reform, the neo-institutional theory of market relations has its own characteristics of development. A unique situation has developed in the Russian economy - in the presence of broad government support, the institutions of small and medium-sized businesses develop very unstable, and their economic dynamic shows high volatility [11-12].

For example, the birth rate of organizations, which has been steadily increasing up to 2008, shows a decrease from 2009 to the present days(in the period up to 2009, the coefficient varied between 115 and 124 units per 1,000 organizations. In July 2020, the value does not exceed 18.1 units per 1,000 organizations). Several factors contribute to this:

a large-scale corporate segment (including one formed due to the massive participation of the state in the economy) reduces the competition opportunities for small and medium-sized businesses;

the presence of foreign policy and foreign economic pressure on the Russian economy destabilizes domestic markets and reduces domestic demand for products and services of small and medium-sized businesses;

the lack of entrepreneurial activity of the population and the low level of innovations in entrepreneurship negatively affects the formation of the strategic potential for the development of this institutional segment;

An increase in various threats and barriers to entry into the market (both external and internal restrictions) leads to a decrease in the level of economic security of entrepreneurial activity [13-14].

Thus, the urgent need for the small and medium-sized business segment is not only the formation of incentives for growth but also the development of optimal and effective tools for strategic management, primarily focused on increasing the level of economic security. Economic security can be considered at the same time as a scale for assessing the effectiveness of managing the functioning and development of small and medium-sized businesses and as a quantitative factor that determines the quality of the formation of the institutional environment, which projects the development trends of all its industries and spheres. Taking into account that large corporate structures are more stable (both due to inertia, scale, and due to significant government support in times of crisis, since they are of strategic importance for maintaining economic stability), and the segment of small and medium-sized businesses can retain the ability to function and develop only due to its high mobility (at the same time it is often limited in access to administrative resources and borrowed sources of financing for operating activities), it seems that this segment is in a great need of improving institutional mechanisms for ensuring economic security. Therefore, in modern Russian conditions, small business is more of a social function of realizing a public good. For an entrepreneur, his activity remains the realization of his talents, skills, and abilities, bringing public benefit, rather than a profitable occupation. Entrepreneurship rather allows the employable population to be employed than to obtain a high entrepreneurial income. Thus, the growth rate of wages in the small business segment in 2018 compared to 2010 amounted to $222.92 \%$, and for the same period, the turnover per employee was $264.71 \%$ (Fig. 1). 
Growth rate in 2018 to $2010, \%$

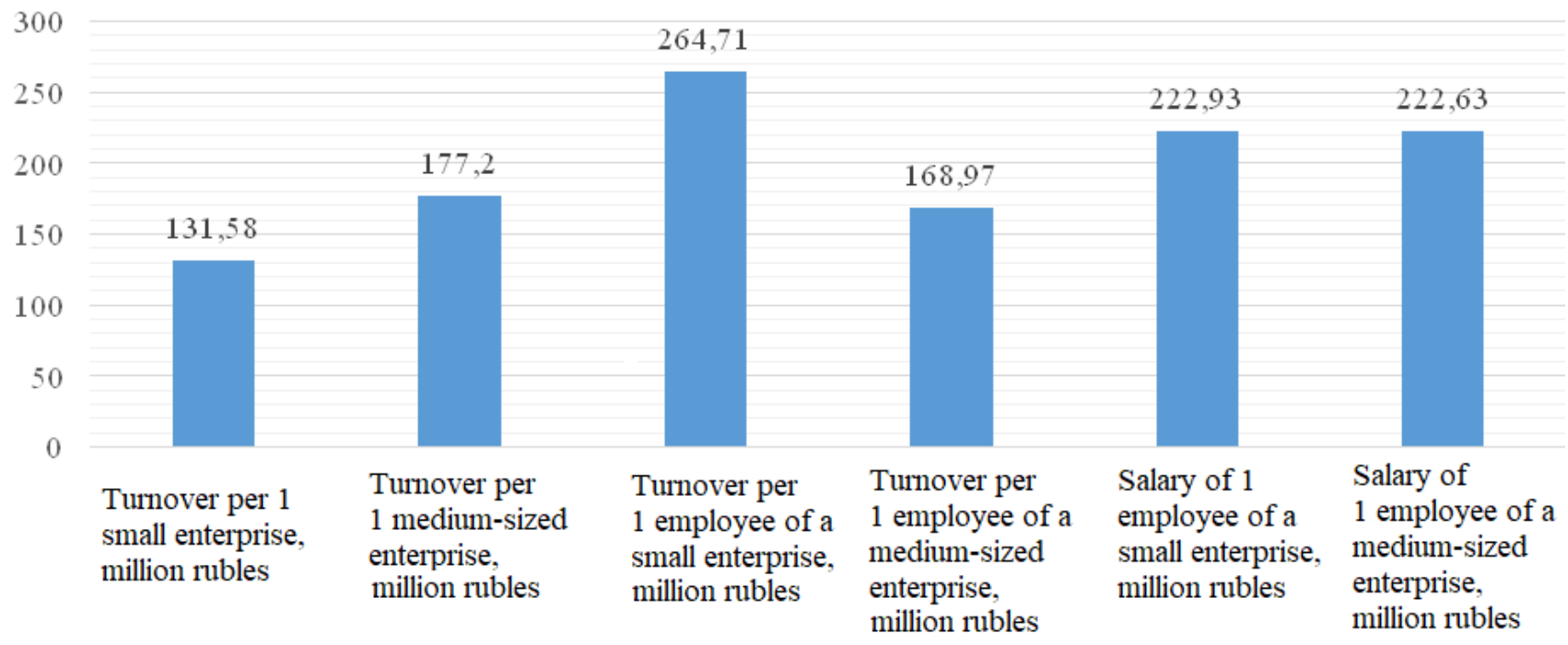

Figure 1. Growth rate of wages, turnover per employee and per 1 enterprise in small and medium-sized businesses in 2018 compared to $2010, \%$ *

*authors' calculations based on data from https://rosstat.gov.ru/folder/210/document/13223

The low level of implementation innovations in small and medium-sized businesses is primarily due to the lack of investment (both state and private). Lack of funds negatively affects the strategic potential for the development of the institutional segment of small and medium-sized businesses (Fig. 2). The leaders of such enterprises are left alone with the problems of business development and the introduction of new technologies. Thus, the largest share of enterprises engaged in technological innovation in the total number of surveyed small enterprises was in the production of computers, electronic and optical products - 19.2\% in 2019. However, in most industries where small businesses operate and develop, this figure does not exceed $10 \%$ (production of computers, electronic and optical products, food and beverage production, clothing and textile products, wood processing and production of wood and cork products, printing activity and copying of information carriers, production of rubber, metallurgical and plastic products, production of motor vehicles, trailers and semi-trailers, production of other vehicles and equipment, furniture production). 


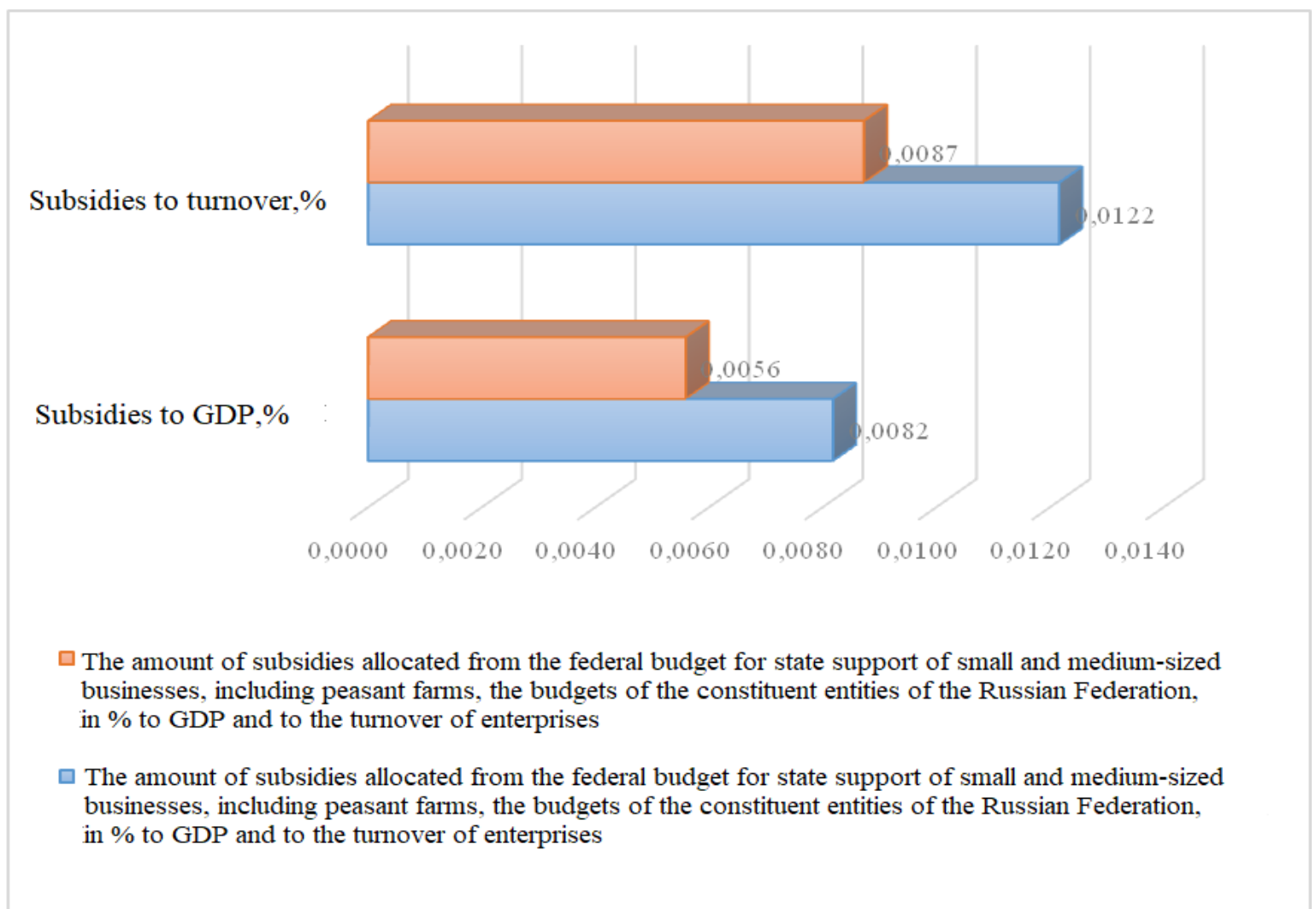

Figure 2 Dynamics of the subsidies' volume allocated from the federal budget for state support of small and medium-sized businesses, including peasant farms, budgets of the constituent entities of the Russian Federation in\% of GDP and in $\%$ of turnover of enterprises in 2017 and 2018.*

* authors' calculations based on data from https://rosstat.gov.ru/folder/210/document/13223

Besides, the leaders of small and medium-sized enterprises have to experience difficulties and high competition with large corporations, which have minimal transaction costs and vast investment opportunities. So, if in 2017 the share of enterprises with high growth potential (enterprises in which the increase in the number of employees or turnover for three years remains at least $10 \%$ per year) in the total number of all enterprises was $1.3 \%$, then in 2019 their share was $1.01 \%$. Expansion, modernization, and the introduction of innovative resources can only be afforded by a large enterprise. Thus, a survey of respondents heads of small businesses over the past 2 years showed an increase in external and internal institutional factors that impede the investment activities of these economic entities (Table 1).

Table 1. Distribution of small businesses according to the assessment of factors limiting investment activities (as a percentage of the total number of organizations) in 2017 and 2018.

\begin{tabular}{|c|c|c|c|}
\hline \multicolumn{1}{|c|}{$\begin{array}{c}\text { Factors limiting } \\
\text { investment activity }\end{array}$} & $\mathbf{2 0 1 7}$ & $\mathbf{2 0 1 8}$ & $\begin{array}{c}\text { 2018 in } \\
\text { comparison } \\
\text { to 2017, \% }\end{array}$ \\
\hline $\begin{array}{l}\text { Insufficient demand for } \\
\text { products }\end{array}$ & 23 & 27 & 117,4 \\
\hline $\begin{array}{l}\text { Imperfect legal framework } \\
\text { regulating investment } \\
\text { processes }\end{array}$ & 21 & 35 & 166,7 \\
\hline
\end{tabular}

\begin{tabular}{|c|c|c|c|}
\hline $\begin{array}{ll}\text { Complex mechanism for } \\
\text { obtaining loans for the } \\
\text { implementation } \\
\text { investment projects }\end{array}$ & 35 & 48 & 137,1 \\
\hline Investment risks & 31 & 47 & 151,6 \\
\hline $\begin{array}{l}\text { High percentage of } \\
\text { commercial loans }\end{array}$ & 41 & 54 & 131,7 \\
\hline $\begin{array}{l}\text { High inflation rate in the } \\
\text { country }\end{array}$ & 38 & 58 & 152,6 \\
\hline $\begin{array}{l}\text { Lack of own financial } \\
\text { resources }\end{array}$ & 44 & 49 & 111,4 \\
\hline $\begin{array}{l}\text { Uncertainty of the economic } \\
\text { situation in the country }\end{array}$ & 42 & 61 & 145,2 \\
\hline
\end{tabular}

To assess the significance of factors in dynamics, the Kendall coefficient was used, the advantage of which is that the nature of the distribution of the compared variables does not play a role in its calculation. The coefficient $\tau$ is designed to work with data obtained in a rank scale and is based on calculating the sum of inversions and coincidences.

Each factor was assigned the ranks of the attribute ' $\mathrm{Y}$ ' and factor ' $\mathrm{X}$ ' to calculate the coefficient. Since the estimates assigned to each pair of this series are positive, the value $"+1 "$ included in $\mathrm{P}$ will be generated only by those pairs whose ranks along $\mathrm{Y}$ form a direct order. Kendall's coefficient is calculated using the formula: 


$$
\tau=\frac{P-Q}{\frac{1}{2} N(N-1)}
$$

Its amount is 0.64 .

To test the null hypothesis about the equality to zero of the general Kendall rank correlation coefficient with the competing hypothesis $\mathrm{H} 1: \tau \neq 0$ at the significance level $\alpha$, it is necessary to determine the critical point:

$$
T_{k p}=z_{k p} \sqrt{\frac{2(2 n+5)}{9 n(n-1)}}
$$

Where $\mathrm{n}$ is the sample size; $\mathrm{Zkp}$ is the critical point of the two-sided critical region, which is found from the table of the Laplace function by the equality $\Phi(\mathrm{Zkp})=(1-\alpha) / 2$. If $|\tau|<\mathrm{Tkp}$ - there is no reason to reject the null hypothesis. The rank correlation link between qualitative features is insignificant.

If $|\tau|>$ Tkp - the null hypothesis is rejected. There is a significant rank correlation between the qualitative characteristics.

Zkp critical point

amounted to: $\Phi(\mathrm{zkp})=0.475$ /

According to the Laplace table, we find $\mathrm{Zkp}=1.96$. The critical point was:

$$
T_{k p}=1.96 \sqrt{\frac{2(2 \cdot 8+5)}{9 \cdot 8(8-1)}}=0.57
$$

Taking into account that $\tau>$ Tkp, we reject the null hypothesis; the rank correlation between the scores on the two tests is considered significant.

Thus, the Kendall coefficient calculations show a direct significant relationship between the factors limiting investment activity. Moreover, such an increase in factors is noticeable precisely in the dynamics of the answers of the respondents - heads of small and medium-sized businesses.

The consequence of Covid-19 is a decrease in the demographics of small and medium enterprises. So, in August 2020, 20.2 thousand organizations were registered (in August 2019 - 23.5 thousand), the number of officially liquidated organizations amounted to 44.1 thousand (in August 2019 - 54.6 thousand. organizations). The number of liquidated entities would have been higher. However, the moratorium on the liquidation of enterprises introduced by the state has slightly slowed down the situation.

\section{RESULTS DISCUSSION}

Thus, in recent years, due to the steady decline in income, the decline in entrepreneurial activity has a significant impact on both the market and consumers. Despite government support measures, small and medium-sized businesses are on the brink of survival. Most entrepreneurs do business not so much for generating income but for realizing their potential. Therefore, the state should stimulate the development of entrepreneurial structures, creating the most loyal working conditions for them. The priority of state policy for such structures should be the development of human capital, its social utility.

The influence of the economic and investment situation in dynamics is considered by using non-parametric methods based on a survey of entrepreneurs conducted by Rosstat.

Thus, the results of the survey in dynamics showed a statistically significant strength of the relationship between the indicators of the business environment favorableness and the time factor of its development.

\section{CONCLUSION}

The development of small and medium-sized businesses is hindered by both external and internal factors. For the growth and development of this sector, it is necessary:

To encourage the creation of labor dynasties, passing on their experience to the younger generation to start independent economic (entrepreneurial) activities;

To stimulate independent management and administration of your business to "work for yourself" to eliminate unproductive losses;

Government assistance in the implementation and investment of new projects;

To implement a self-employment project to monetize the potential of entrepreneurial risk and chance, search for new forms of consumer sale of goods;

To activate the self-realization of entrepreneurs in the format of an independent entity capable of responsible multifaceted activity, taking into account not only economic but also social interests and restrictions; To create opportunities and "test of strength" for entrepreneurs and, in this regard, the creation of schools for qualified training/approbation in terms of organizing entrepreneurial activities, the possibility of using multiformat employment, and economic activity (employment/participation in projects/self-employment).

The state should create effective institutions that will contribute to the development of small and medium-sized businesses. A promising area of infrastructural support for the institution of small and medium-sized businesses, including for the effective use of human capital, is the use of the scientific and educational infrastructure of the regional economy as a promising microenvironment for the functioning and development of SMEs based on the predominant use of off-budget sources of funding, the formation of integrated localized structures, and results of functioning and growth that are significant for the regional economy.

\section{ACKNOWLEDGMENT}

This study was carried out in the framework of research work on the topic of "Development of methodological tools for assessing the quality of the institutional reforms in the field of 
entrepreneurship in terms of development the digital environment (for example, branches of trade, manufacturing industries, etc.)" from the funds of the "REU them. G. V. Plekhanov" (order No. 642 from 01.06.2020 G.)

\section{REFERENCES}

[1] A.S. Tarasevich, Institutional forms of entrepreneurial activity: formation and development: Dis. Cand. econom. Sciences: 08.00.01, Samara, 2004 168 с. РГБ ОД, 61:05-8/1808/

http://www.dslib.net/econom-teoria/institucionalnyeformy-predprinimatelskoj-dejatelnosti-stanovlenie-irazvitie.html

[2] R.S. Davletova, R.A. Kolovertnov, R.V. Faizullin, The impact of the external environment on the strategic planning of the development of an industrial enterprise, Economics and entrepreneurship, №7, 2013.

[3] R. Olzhabaeva, Dialectics of the development of the theory of strategic management in the 20th century, Electronic resource.

[4] G.V. Shirokova, Life Cycles of Russian Entrepreneurial Firms: Research Methodology and Main Stages, Ph.D. Dissertation in Economics.

[5] V. I. Oseichuk, Theory of Public Administration: Textbook and Workshop for Bachelor's and Master's Degree, Series: Bachelor and Master. Academic course, Tyumen State University, Yurayt Publishing House, 2016, P. 342.

[6] State and municipal administration: textbook and workshop for an academic bachelor's degree, V. P. Vasiliev, N. G. Dekhanova, N. A. Los, Yu. A. Kholodenko, Series: Bachelor. Academic course, 3rd ed., Rev. and additional, Yurayt Publishing House, 2019, P. 325 c.

[7] State and municipal administration: textbook and workshop for academic bachelor's degree, V. P. Vasiliev, N. G. Dekhanova, N. A. Los, Yu. A. Kholodenko, Series: Bachelor. Academic course, 3rd ed., Rev. and additional, Yurayt Publishing House, 2019, P. 325.

[8] Z.J. Acs, C. Armington, Entrepreneurship, geography, and American economic growth. Cambridge University Press, 2006, Terziovski M. Innovation practice and its performance implications in small and medium enterprises (SMEs) in the manufacturing sector: a resource-based view, Strategic Management Journal, 2010, Vol. 31, No 8, pp. 892-902.

[9] N.I. Gulbina, On the classification of the main currents of institutional theory, Bulletin of Tomsk State University, 2009, Economics, №4 (8), pp. 77-86.

[10] S. I. Arkhiereev, Institutional interactions as the basis of network interactions and problems of posttransformation market economy, Journal of institutional studies, T. 4, № 1, 2012, pp. 9-24.

[11] N.S. Bondarev, Institutional Transformation in Agriculture: Theory and Methodology, Abstract of the Dissertation for the Degree of Doctor of Economics.

[12] A.A. Savichev, Factors and conditions for sustainable development of small and medium-sized businesses, University Bulletin, №4 2015, pp. 144- 149.

[13] T.I. Bukhtiyarova, A.V. Dubynina, D.G. Demyanov, K.A. Savechenkova, A.A. Yakushev, Configuration of problems of managing the development of small and medium-sized businesses: monograph, Chelyabinsk branch of the Financial University, Chelyabinsk, 2015, P. 215.

[14] V.P. Nevmyvako, Institutional Mechanisms for Ensuring Economic Security of the Functioning and Development of Small / Medium-Sized Businesses, Abstract of the Dissertation for the Degree of Candidate of Economic Sciences. 